\title{
Cuando el morbo no abandona las portadas. La construcción de noticias en torno al feminicidio en la prensa sanjuanina
}

\author{
When the sensationalism does not leave the covers. The \\ construction of news about feminicide in the press in San Juan
}

Tatiana Marisel Pizarro tatianamariselpizarro@gmail.com

http://orcid.org/0000-0002-3701-5156

Instituto de Investigaciones Socioeconómicas; Facultad de Ciencias Sociales; Universidad Nacional de San Juan/ Consejo Nacional de Investigaciones Científicas y Técnicas (Argentina)

\section{Resumen}

Con este ensayo se pretende mostrar la ausencia de perspectiva de género en la prensa sanjuanina al momento de la construcción de la noticia, particularmente en los casos de feminicidios. Para esto, este artículo se enfoca en el análisis del tratamiento informativo que Diario de Cuyo realizó en torno a los dos feminicidios ocurridos en la segunda quincena de junio de 2018 en San Juan, Argentina. Las técnicas utilizadas en el estudio fueron la recolección, sistematización y análisis del corpus previamente detallado.

En la actualidad, estos crímenes han tomado gran visibilidad a partir de movimientos como el \#NiUnaMenos, periodistas militantes feministas y todas/os los que demanden por una nueva 
forma de comunicar, más humana, más realista, más solidaria y menos espectacularizante o amarillista.

Palabras clave: Feminicidio; prensa sensacionalista; construcción de la noticia; perspectiva de género.

Abstract

This essay aims to show the absence of gender perspective in the San Juan press at the moment of the construction of the news, particularly in cases of feminicide. For this, this paper focuses on the analysis of the informative treatment carried out by Diario de Cuyo around the two femicides that occurred during the second half of June 2018 in San Juan, Argentina.

The techniques used in the study were the collection, systematization and analysis of the previously detailed corpus. Currently, these crimes have taken great visibility from movements such as \#NiUnaMenos, militant feminist journalists and all those whom demand a new way of communicating, more human, more realistic, more supportive and less spectacularizing or sensationalist.

Keywords: Feminicide; tabloid press; construction of the news; gender perspective.

Este ensayo surge con el propósito de mostrar la urgente necesidad de que los medios de comunicación adopten una perspectiva de género en la construcción de las noticias, especialmente en aquellas que tienen como foco informativo a los feminicidios.

En los últimos años, la comunicación ha estado vinculada a los estudios de género con el objetivo de enseñar cómo son expuestas y representadas las mujeres en los medios de comunicación masivos y cómo se han naturalizado ciertas prácticas a la hora de difundir determinados estereotipos relacionados a lo femenino.

De este modo, lo que pretende este trabajo es problematizar la manera en que los medios de comunicación informan desde una pedagogía de la crueldad planteada por Rita Segato y la violencia simbólica bosquejada por Pierre Bourdieu. Para lograrlo, se pone el foco en cómo Diario de Cuyo construye los discursos en torno a los feminicidios ocurridos en junio de 2018 , sin utilizar esta figura en sus notas, sino que se refiere a éstos como homicidios o crímenes 
pasionales. Por esto, la pregunta que atraviesa este paper es: ¿cuáles son las herramientas que utiliza Diario de Cuyo para la construcción de este tipo de informaciones?

Para lograr responder este interrogante, metodológicamente se trabajó con el enfoque cualitativo a través de la técnica de la etnografía mediática (1), que permitió la recolección de las notas sobre feminicidios y analizar las características de las publicaciones. Es así que se analizaron noticias en las que hay una clara visión falocéntrica al momento de definir y presentara la víctima, legitimando a través de lo discursivo relaciones de poder de hombres sobre mujeres. Es oportuno mencionar que las notas recabadas corresponden a dos feminicidios sucedidos durante el mismo mes en la provincia de San Juan, ambos hechos fueron tratados de un modo distinto por las características de las víctimas.

\section{Género y violencia}

En la actualidad, la violencia es un tópico implícito en los procesos de sociabilización presente en toda relación consolidada desde lo masculino: interacciones sociales, amorosas, laborales, estudiantiles, etcétera. Este tipo de relaciones están dadas desde el poder naturalizado, instaurado e impuesto en la sociedad de la que somos parte.

Mediante la violencia simbólica, presentada por Pierre Bourdieu, es posible observar esta práctica desde el género -con especial énfasis en lo femenino-, mediante el poder patriarcal asumido como natural. Distintas instituciones -Estado, familia, Iglesia y escuela- han implantado y legitimado este tipo de violencia simbólica como una

\footnotetext{
violencia amortiguada, insensible e invisible para sus propias víctimas, que se ejerce esencialmente a través de los caminos puramente simbólicos de la comunicación y del conocimiento o, más exactamente, del desconocimiento, del reconocimiento o en último término del sentimiento (Bourdieu, 2000: 12).
}

En función a esto, es necesario entender cómo el inconsciente actúa en base a un esquema androcéntrico, ya que es la dominación masculina la que impera en la percepción del mundo de la mayoría de las personas que son parte de este sistema (Bourdieu, 2000: 17). En este sentido, Judith Butler plantea que el foco de rever al género se encuentra en lo imperante de deshacerlo como una construcción normativa o un pre-supuesto impuesto. Es decir, esa nueva mirada es ver al género "haciéndose" con o para otro -aunque éste sea imaginario-, construyéndose socialmente, del mismo modo refiriéndose a la sexualidad (Butler, 2006: 38). 
En este sentido, puede observarse que tanto el género como la sexualidad se perciben como algo propio, íntimo, pero que en simultáneo es una construcción social que está presente mediante el reconocimiento. Por esto, Butler propone que el género y la sexualidad deben ser descriptos "como maneras de ser desposeído, maneras de ser para otro o, de hecho, en virtud de otro" (2006:38). En otras palabras,

los proyectos de reconocimiento que se encuentra a nuestra disposición son aquellos que "deshacen" a la persona al conferirle reconocimiento, o que la "deshacen" al negarle reconocimiento, entonces el reconocimiento se convierte en una sede del poder mediante la cual se produce lo humano de forma diferencial (Butler, 2006: 15)

Respecto a esto, si el nombrar es otorgar existencia, pertenencia, se demuestra cómo en el uso cotidiano del lenguaje la mujer es excluida en un contrato sexual implícito en el hablar cotidiano. Es decir, las mujeres deben presentarse a sí mismas como objeto excluido, ya que sin percibirse a sí mismas como tal, esa exclusión pierde sentido; en otras palabras, "las mujeres deben reconocer la ficción política y hablar su lenguaje aún cuando los términos del contrato original las excluya de la conversación fraternal" (Pateman, 1995: 303). Es imposible, entonces, mirar a las personas fuera del género -como categoría impuesta socialmente naturalizada-. Ante la imposición de este escenario, se percibe cómo las mujeres son despojadas de las decisiones sobre sus vidas e, incluso, sobre sus cuerpos.

Es preciso, entonces, traer a colación a Foucault con su noción de discursos construidos bajo determinadas leyes y normas legitimadas cuando se asociadas al género. En esta línea, el autor resalta la relación desigual existente entre hombres y mujeres, así como los prejuicios instaurados -y legitimados- en la Iglesia y la familia, como punto de partida y naturalización, para luego fijarse en la escuela y en el Estado mediante sus leyes (Foucault, 2002). Es decir, la familia, la Iglesia, el Estado y la Escuela son las instituciones en las que se han fundado la desigualdad y la invisibilización de las mujeres, instaurándose desde un espacio común y natural la violencia hacia ellas.

\section{Género y discurso}

En este punto es fundamental aportar la mirada de van Dijk (2003) respecto a la ideología y cómo se enuncia en el discurso. El autor sugiere ver al discurso como esa práctica "condicionada por las ideologías en el uso del lenguaje y del discurso y este uso, 
simultáneamente, influye en la forma de adquirir, aprender o modificar las ideologías" (van Dijk, 2003: 16). Es preciso, entonces, reflexionar acerca de que gran parte de los discursos surgen a partir de lo que se escucha en un determinado grupo o asimila desde las primeras lecturas realizadas. Consecuentemente, las ideologías deben ser asimiladas como la base de la "memoria social" compartida por grupos y no como socioculturales, debido que se comprende que no todo el mundo las acepta sino que, precisamente, éstas generan "diferencias de opinión, conflictos y luchas" (Ibídem: 23).

Cada discurso se erige a partir de la intencionalidad de comunicar y este acto acopia sentidos y realidades. Por ejemplo, cuando se habla de mujeres, los pareceres que pueden llegar a transigir son en torno a la pobreza, la desigualdad y la marginalidad; asimismo, cuando se habla de violencia, la mujer puede ser vista ante todo desde su papel como madre. Este discurso patriarcal instaurado no permite ver a la mujer como autónoma e independiente, sino desde su relación con la familia o su pareja. En este punto es plausible evidenciar que los mensajes difundidos por los medios de comunicación son erigidos desde una mirada patriarcal cuando se tratan de feminicidios, ya que son discursos que tienen como base crímenes de odio contra las mujerespero con sesgos minimizadores del hecho.

Según el Observatorio de Femicidios Adriana Zambrano (2012), de la ONG Casa del Encuentro, en Argentina, en 2011, una mujer era asesinada cada treinta horas. Es decir, en el transcurso de ese año hubo 237 femicidios de mujeres y niñas y 283 hijos/as fueron víctimas colaterales del femicidio ( 174 hijos/as menores, 42 adultos/as y en 67 casos no se registra sexo o edad). Esta realidad impulsó a que el 15 de noviembre de 2012, la Cámara de Diputados sancionara una norma que agrava la pena de homicidio cuando el sujeto sea una mujer. Así, se incluyó en el Código Penal Argentino la figura del femicidio, pero éste no es incorporado como figura penal autónoma sino como un tipo agravado de homicidio.

Éste es un punto clave, la socióloga feminista Marcela Lagarde hace la distinción entre feminicidio y femicidio, ya que esta última es una forma homóloga a homicidio y sólo se circunscribe en el asesinato de mujeres. Con feminicidio, por el contrario, define a todas aquellas violaciones a los derechos de las mujeres:

El feminicidio es el genocidio contra mujeres y sucede cuando las condiciones históricas generan prácticas sociales que permiten atentados violentos contra la integridad, la salud, las libertades y la vida de niñas y mujeres. En el feminicidio concurren en tiempo y espacio, daños contra niñas y mujeres realizados por conocidos y desconocidos, por violentos, -en ocasiones violadores-, y asesinos individuales y grupales, ocasionales o profesionales, que conducen a la muerte cruel de algunas de las víctimas. No todos los crímenes son 
concertados o realizados por asesinos seriales: los hay seriales e individuales, algunos son cometidos por conocidos: parejas, ex parejas parientes, novios, esposos, acompañantes, familiares, visitas, colegas y compañeros de trabajo; también son perpetrados por desconocidos y anónimos, y por grupos mafiosos de delincuentes ligados a modos de vida violentos y criminales. Sin embargo, todos tienen en común que las mujeres son usables, prescindibles, maltratables y desechables. $\mathrm{Y}$, desde luego, todos coinciden en su infinita crueldad y son de hecho crímenes de odio en contra de las mujeres (Lagarde, 2012: 216).

Las precursoras del término fueron Diana Russell y Jane Caputi en su artículo Speaking the Unspeakable, en el que subrayan que aquellos actos violentos que culminan con la muerte de las mujeres son feminicidios:

El feminicidio representa el extremo de un continuum de terror anti-femenino e incluye una amplia variedad de abusos verbales y físicos, tales como violación, tortura, esclavitud sexual (particularmente por prostitución), abuso sexual infantil incestuoso o extra-familiar, golpizas físicas y emocionales, Acoso sexual (por teléfono, en las calles, en la oficina, y en el aula), mutilación genital (clitoridectomías, escisión, infibulaciones), operaciones ginecológicas desnecesarias (histerectomías gratuitas), heterosexualidad forzada, esterilización forzada, maternidad forzada (por la criminalización de la contracepción y del aborto), psicocirugía, negación de comida para mujeres en algunas culturas, cirugía plástica, y otras mutilaciones en nombre del embellecimiento. Siempre que estas formas de terrorismo resultan en muerte, ellas se transforman en feminicidios (Caputi y Russell, 1992: 15).

Es decir, las autoras hacen hincapié en que el objetivo de la violencia ejercida por parte de los varones -sea a propósito o no- es mantener la supremacía masculina. Este concepto permite reconocer la desigualdad, subordinación, marginalidad y riesgo sufridos por las mujeres sólo por ser mujeres. La politización de estos homicidios es imprescindible debido que se pone énfasis en revelar cómo poder y masculinidad son sinónimos que pregonan desprecio por las mujeres y por todo lo asociado a lo femenino.

Por esto, lo que en este ensayo se expone es el modo en que el principal medio gráfico de la provincia de San Juan difunde los casos de feminicidio; en este sentido, el análisis comprende a las notas publicadas sobre los dos asesinatos de mujeres ocurridos en el lapso de la última quincena de junio de 2018 en la provincia antes mencionada. La muestra corresponde a los discursos obtenidos en la página web del diario -en muchos casos, coincide con la publicada en el diario impreso-. El cúmulo de noticias es analizado tomando en consideración cuatro ejes: 
violencia sexual, crimen de odio, crimen pasional y asesinato. Esto se debe a que el medio prácticamente no usa la figura de feminicidio, lo que permite ejemplificar las distintas construcciones de sentido que pone en juego el medio gráfico.

\section{Yamila}

El 18 de junio de 2018, Diario de Cuyo difunde en su página web una nota sin firma que dice "Encontraron a una joven muerta en un baldío". Se especifica que "aunque no trascendieron mayores detalles, el cuerpo presentaba signos de violencia extrema". Horas más tarde, la información se actualiza espectacuralizando el crimen: "Macabro: el cuerpo de la joven hallado en el baldío no tiene brazos y le falta parte del rostro". Con el transcurso de las horas, nuevamente en una nota sin firma, el medio comunica en su página web que "Reforzarán el rastrillaje para hallar las partes mutiladas de la mujer", noticia en la que difunden datos escabrosos e innecesarios a la hora de comunicar:

No hay dudas que el o los asesinos quisieron que el crimen sea perfecto. La zona es tranquila y con casi nada de tránsito. Entrar y salir es sencillo, en cuestión de minutos se llega a una arteria con acceso a zonas urbanas. En la policía están convencidos que la faena la ejecutaron en otro sitio y al baldío fueron a descartar el cuerpo. La cara fue desfigurada. La desollaron, le arrancaron la piel y el cuero cabelludo. Le cortaron los brazos con un cuchillo filoso y por la altura en que lo realizaron, sospechan que hay alguna marca (tatuaje o indicio que identifique a la persona) que quisieron deshacerse (Diario de Cuyo, 18 de junio de 2018).

Al día siguiente, el medio continuó "informando" en esa línea: "La matan, le sacan el rostro, le cortan los brazos y tiran el cuerpo en un basural", "la víctima, al parecer una mujer joven, no tenía rostro porque se lo habían arrancado con algún elemento filoso. Tampoco tenía uno de sus ojos, sus brazos habían sido "despostados" a la altura del hombro" (19 de junio de 2018).

El 20 de junio, el diario continúa difundiendo datos escabrosos del crimen -en ningún momento se refiere a éste como feminicidio-: "La mujer mutilada tenía los pantalones bajos y no descartan un ataque sexual" (20 de junio de 2018), pero agrega un nuevo elemento: "Creen que la mujer mutilada fue madre recientemente". Durante la mañana del 20 de junio, el Jefe de Policía de San Juan realiza una rueda de prensa con el objetivo de brindar mayor información sobre quien asesinó a la mujer. En la conferencia, tomada por el diario, se hizo foco en el dicho 
de la autoridad policial: "estamos trabajando por los caminos correctos, con el objetivo de determinar si se trató de un crimen pasional, por venganza o por encargo". Nuevamente, no se habla de feminicidio.

A las 18 horas del mismo día, Diario de Cuyo informa acerca del descubrimiento de la identidad de la víctima: "Identificaron a la mujer mutilada: Yamila Pérez, era de Concepción y fue madre en mayo. Altas fuentes de la investigación informaron el nombre de la víctima. Investigan si la mujer ejercía la prostitución". Es este último dato el que hace que el medio ponga el foco de sus notas en la víctima y los distintos aspectos de su vida, por ejemplo: "De acuerdo a lo que pudo observar DIARIO DE CUYO la mujer tenía una fuerte actividad en las redes sociales, en particular en Facebook con al menos 4 cuentas" (20 de junio de 2018), en la nota hace una descripción de cada perfil con el que Yamila publicaba.

Ya con el descubrimiento de su identidad, en cada nota el medio la mataba simbólicamente una y otra vez. Detallaba pormenorizadamente el estado de su cuerpo y cómo habían asesinado a Yamila: “'despostó' los brazos a la altura de los hombros y realizó un corte horizontal sobre las mamas, para sacarle la piel del rostro y la cabeza hacia arriba (en eso arrancó su ojo derecho) hasta concluir con otro corte de lado a lado en la espalda" (20 de junio de 2018). Pero el diario no se conformó con esto, sino que decidió publicar informaciones sobre una de las hijas de Yamila: "Una de sus hijas, abusada" (20 de junio de 2018), nota en la que se hace hincapié en lo vivido por la hija mayor de la mujer.

En el lapso de tres días $-18,19$ y 20 de junio- se publicaron 19 notas referidas al crimen de Yamila.

\section{Leila}

El 28 de junio de 2018, otro cuerpo fue encontrado en un descampado. Se trataba de Leila, una mujer de 24 años, cuya identidad fue descubierta a pocas horas de ser encontrado su cuerpo. Las notas que Diario de Cuyo conservaban la misma perspectiva al informar, sólo había cambiado la víctima: "Creen que Leila sufrió un ataque sexual y terminaron con ella matándola a golpes. Tenía 24 años y era madre de una nena de 3. La hallaron ayer en una acequia, tapada con ramas, tierras y hojas" (28 de junio de 2018). La describieron en una cita de allegados como alguien que "no estudiaba y no tenía un trabajo fijo, 'si aparecía algo, agarraba', dijeron" (29 de junio de 2018). Sobre su cuerpo: "la causa de la muerte fue por un 
fuerte golpe en la cabeza (tenía sangre en todo su rostro), aunque unas marcas en el cuello de la víctima pueden alimentar la teoría que la asfixiaron" (29 de junio de 2018).

"A Leila le dieron 2 golpes en la cabeza y 4 cuchillazos, uno de ellos la desangró", dice el título de la nota de la edición impresa reproducida por la página web del medio analizado el 29 de junio de 2018. En la misma línea, continuó difundiendo datos escabrosos del estado en el que se encontraba el cuerpo de Leila:

\begin{abstract}
No había marcas de un ataque sexual en sus genitales. En su cabeza presentaba un golpe y otro más que la lastimó provocados con un objeto romo, tal vez un puño. En la espalda, tenía las marcas de dos puntazos, uno de los cuales le había perforado el intestino grueso y desató un proceso infeccioso. $Y$ en el pecho presentaba otros dos puntazos, uno de ellos letal porque le dañó el corazón y el pulmón causándole una hemorragia devastadora (Diario de Cuyo, 29 de junio de 2018).
\end{abstract}

Debido a pruebas que comprometían como autor del feminicidio de Leila a su ex pareja, el medio en su página web tituló el 29 de junio de 2018: "El padre de la hija de Leila, contra las cuerdas por pruebas clave", para luego ampliarlo dicho con una nota que presentaban al sospechoso como "Tranquilo, buen padre e incondicional con Leila, así definen al sospechoso del crimen". En este punto, es oportuno resaltar cómo el diario se aleja, mencionando a agentes que son los responsables de esa suposición, esto se infiere porque el medio únicamente publica el hecho y busca personas que ratifiquen su posicionamiento, sin olvidar la premisa utópica de la objetividad que los medios la adoptan como propia e inherente a su quehacer.

En el lapso de cinco días, se publicaron 18 notas referidas al asesinato de Leila.

\title{
Al pan, pan y a los crímenes de mujeres, feminicidios
}

A ninguno de los casos presentados, Diario de Cuyo los definió como feminicidios. Es que este es un tema rezagado para el medio gráfico. Aparentemente, el diario decide no llamar feminicidios al crimen de una mujer con indiscutibles signos de odio asociado al género. De este modo, lo que hace es asociarlo a asesinatos, sea cual sea su característica, lo que provoca una invisibilización del maltrato a la mujer como una problemática social que desencadena en muchos casos en feminicidios. En este sentido, Stella Martini explica que: 
los medios evalúan el valor de la noticia como Noticia práctica, como impacto emocional y como formadora de la opinión pública. Estos rasgos apuntan a la concepción de la noticia como un servicio público, que construye los datos que necesita la sociedad en su vida cotidiana; a la conmoción y también a la empatía entre la construcción periodística y el público, que hace a la noticia más cercana y creíble, y al papel jerarquizador de los medios en relación con los asuntos públicos. Un hecho se vuelve noticia por el efecto y su función social, entendiendo por efecto las huellas que dejan las noticias, en comentarios, conversaciones y debate y en la producción de otros hechos, y como función social, por el valor de la Noticia sobre la vida de los individuos. Por eso, el hecho que repercute más es más noticia, lo mismo que el hecho que repercute en más hechos también lo es (2000: 12).

En los casos analizados, el medio publicó prácticamente la misma cantidad de notas. Ahora bien, que el diario difunda como asesinatos estos crímenes tiene que ver con que éste pone foco en la inmediatez de la información y no hace un análisis -o distinción- de un hecho a otro por ser patriarcal, sino que prioriza que la noticia sea publicada. Al optar por este modo de comunicar, el medio naturaliza estos hechos violentos contra las mujeres, lo que recae en una familiarización de la sociedad regida por la heteronormatividad con la que se justifica que la mujer sea presentada como un ser inferior, en una sociedad en la que si matan a dos en el mismo mes no evidencia nada. En otras palabras, al no especificar que las agresiones realmente son feminicidios, la intencionalidad del medio es minimizar la problemática a través de la narrativa y lo logra por el poder que le ha sido asignado como generador de opinión pública; el poder que permanece en disputa, cuando no referimos al discurso, y que ha sido asignado a él (Foucault, 1970).

Diario de Cuyo, en este sentido, construyó sus discursos con una clara pedagogía de la crueldad, definida por Rita Segato como esa crueldad "aplicada a cuerpos no guerreros, sobre todo, se aísla y potencia la función propiamente expresiva de estos crímenes, función que, como se ha destacado anteriormente, es inherente e indisociable en todos los tipos de violencia de género" (2013: 24). En simultáneo, la práctica de esta crueldad

\begin{abstract}
juega un papel en una economía simbólica que sustenta y alimenta la economía material propia del mercado en esta fase apocalíptica del capital, pues escenifica una pedagogía perversa, lo que he llamado más arriba de una pedagogía de la crueldad, al promover y acostumbrar al espectáculo de la rapiña de la vida hasta el desecho, hasta dejar solo restos. Es la propagación de la idea del goce como secuencia de consumo y desecho (Segato, 2013: 110).
\end{abstract}


Al referirse a la muerte de Yamila, el medio usa el término crimen de odio, con el que hace alusión a que fue víctima de una violencia incontrolable hacia su cuerpo. Por otro lado, para referirse a la muerte de Leila, el diario se refiere a ésta como consecuencia de un crimen pasional, en el que la violencia se instala en la pareja, excluyendo que el motivo sea la violencia de género o machista, con lo que en cierta manera el medio cede a que el hecho sea justificado en algún punto. Es así que el discurso actúa familiarizando ciertos sentidos y formando verdades mediante la intencionalidad del medio (Ricoeur, 1988).

En este punto es necesario citar también a Rita Segato con su interpretación de crímenes de odio, refiriéndose a los feminicidios que la autora analizó en Ciudad de Juárez, pero cuyas consideraciones afín a los objetivos de este ensayo:

\begin{abstract}
Inspirada en este modelo que tiene en cuenta y enfatiza el papel de la coordenada horizontal de interlocución entre miembros de la fratría, tiendo a no entender los feminicidios de Juárez como crímenes en los que el odio hacia la víctima es el factor predominante. No discuto que la misoginia, en el sentido estricto de desprecio a la mujer, sea generalizada en el ambiente donde los crímenes tienen lugar. Pero estoy convencida de que la víctima es el desecho del proceso, una pieza descartable, y de que condicionamientos y exigencias extremas para atravesar el umbral de la pertenencia al grupo de pares se encuentran por detrás del enigma de Ciudad Juárez. Quienes dominan la escena son los otros hombres y no la víctima, cuyo papel es ser consumida para satisfacer la demanda del grupo de pares. Los interlocutores privilegiados en esta escena son los iguales, sean éstos aliados o competidores: los miembros de la fratría mafiosa, para garantizar la pertenencia y celebrar su pacto; los antagonistas, para exhibir poder frente a los competidores en los negocios, las autoridades locales, las autoridades federales, los activistas, académicos y periodistas que osen inmiscuirse en el sagrado dominio, los parientes subalternos -padres, hermanos, amigos- de las víctimas (2013: 26).
\end{abstract}

El 30 de junio de 2018, la agrupación \#NiUnaMenos y Asociación de Mujeres Meretrices Argentinas (Ammar) convocaron a una marcha para pedir justicia por Leila y Yamila. Más de 300 personas asistieron al pedido. Al momento de informar sobre la marcha, Diario de Cuyo sólo focalizó la nota en Leila: "El homicidio de Leila: pañuelos y velas en un reclamo de Justicia"; sin mencionar en ningún momento a Yamila.

Un punto importante en esta noticia y sobre Yamila es que el medio obvia lo sucedido, ausenta el pedido de justicia por su muerte, a pesar de los signos de crimen de odio que sufrió. Acorde a esto, Stella Martini plantea que: 
Se debe insistir en que ya no se trata de rastrear e identificar los lugares que funcionan como "cuellos de botella" en donde cierta Noticia queda atascada y por tanto desechada de las agendas temáticas de un medio, sino de distinguir en el conjunto de la tarea productiva los valores que hacen noticiable un acontecimiento y el significado que tales valores adquieren (y el modo como aparecen rutinizados y naturalizados) en una sala de redacción, en interrelación con las expectativas y las series interpretativas de la sociedad y los estados de la opinión pública (2000: 10).

De este modo, desde el lugar privilegiado en el que se ubica el medio, se establece una línea divisoria entre ellos-nosotros (Tilly, 2006). A través de los discursos enseñados se pueden observar los esquemas propuestos por Bourdieu (2000) sobre la violencia simbólica, ya que asesinar a una mujer es asumido por este diario como algo normal y no como una consecuencia de ser parte de una sociedad patriarcal.

En ambos casos, Diario de Cuyo hizo una exposición textual de lo que las fuerzas policiales le informaron sobre los feminicidios, siendo explícita y cruda la transmisión directa de los pormenores de los hechos al público. En este punto es donde cobra sentido la intención en el discurso, expresión verbal de la intención (Ricoeur, 1988: 40) ya que existe mayor detalle en la construcción de la noticia y sus datos. Además, "el lenguaje simplifica la cosa designada reduciéndola a una única característica; desmiembra el objeto, destroza su unidad orgánica y trata sus partes" (Zizek, 2009: 79). Por lo que cuando se habla de la mujer se justifica -o naturaliza- que sea sobre las formas en las que ha sido violentada es decir, apuñalada, estrangulada, golpeada, etcétera. Y lo riesgoso de que el medio cree un status quo de las mujeres únicamente en relación a la violencia es que por su poder se convierte en una verdad inamovible y en un sentido común.

Por otro lado, como puede inferirse en las notas mencionadas los actores principales son los agresores (desconocido/a en el caso de Yamila) y el medio de comunicación -Diario de Cuyoque decide invisibilizar a las mujeres violentadas. Muy pocas veces se refiere a las víctimas por su nombre, sino que usa un genérico. En el caso de Yamila, se refiere a ella como "la mujer mutilada" u opta por reducirla a "el cuerpo"; en el caso de Leila: "la joven", "la joven madre", "la mujer". Según Vasilachis (1997) "esas metáforas impiden al lector individualizar a los sujetos de la acción y su anonimato será mayor en la medida en que el lector no pueda vincularlos con su experiencia inmediata de semejantes" (p. 46), lo que explicaría el motivo por el que Diario de Cuyo no presenta estos casos como feminicidios, permitiendo ver una problemática social en su conjunto, sino que los presenta como casos aislados de violencia contra la mujer. 
En este punto se puede identificar la construcción falocéntrica que Diario de Cuyo hace en su discurso, debido que adopta un papel de difusor de las relaciones de poder dadas en la cotidianeidad. Al respecto Bourdieu expone que:

\begin{abstract}
a través del principio de división fundamental entre lo masculino, activo, y lo femenino, pasivo, y ese principio crea, organiza, expresa y dirige el deseo, el deseo masculino como deseo de posesión, como dominación erótica y el deseo femenino como deseo de la dominación masculina, como subordinación erotizada, o incluso, en su límite, reconocimiento erotizado de la dominación (2000: 34).
\end{abstract}

Otra constante en las noticias publicadas es que ambas mujeres víctimas de feminicidio pertenecieron a sectores populares de San Juan -Chimbas y Ullum-, lugares en los que mediante el discurso es presumida implícitamente la violencia, innata en la población pobre. En simultáneo, en ambos casos, se destacó que el papel de madre de Yamila -madre prostituta- y Leila -madre que no estudió y vivía de trabajos temporarios-.

En el Diario de Cuyo, tanto Yamila como Leila han sido construidas desde la marginalidad, ofreciendo una imagen estandarizada de maternidad, miseria y sumisión, de este modo exhiben que quienes son víctimas de este tipo de crímenes son ellas, las pobres. Estos presupuestos de minimización son los que hacen visible la línea editorial del diario y la manera en que el medio fomenta y reproduce lo femenino, por lo que resulta dificultoso esperar de este diario una imagen de la mujer fuera de los parámetros que ha planteado -mujer/objeto, victimización e invisibilización-. Con los discursos creados y difundidos por Diario de Cuyo reluce ese sentido común que expresa que la mujer es asesinada por no cumplir con ese estatus quo establecido en el ser mujer: Yamila era prostituta y Leila salía de noche sin avisar adónde iba. Es necesario y preciso subrayar que ni en las notas publicadas sobre Yamila ni en las de Leila, el medio se refirió a sus muertes como feminicidios. Con esto, el diario construye narrativas que sugieren una justificación: en el caso de Yamila, una venganza; con Leila, los celos de su ex pareja.

Respecto al cómo comunican los medios los casos de feminicidios, Rita Segato sostiene:

No podemos entender la violencia como nos la presentan los medios, es decir, como dispersa, mediatizada como anómala y, en algunos casos, como esporádica. Tenemos que percibir la sistematicidad de esta gigantesca estructura que vincula redomas aparentemente muy distantes de la sociedad y atrapa a la propia democracia representativa (2013: 49). 
Por supuesto, la perspectiva presentada por los medios de comunicación no es precisamente la verdadera, pero son las relaciones y realidades que propone el medio. Sobre este punto, Vasilachis explica que "el lenguaje es un medio de coordinación de la acción arriesgada y costoso, pues el significado de cada acto de habla no puede desengancharse del complejo horizonte de sentido del mundo de la vida" (1997: 82-83). A partir de los casos presentados puede observarse que la violencia de género y los feminicidios son un reflejo de parte de la realidad, pero esa realidad es expresada de acuerdo a los escenarios y características de las víctimas que el medio plantea.

\section{Reflexiones finales}

En este ensayo se puso en manifiesto cómo los medios configuran esquemas de exclusión en los que se evidencia la violencia simbólica a la que es sometida la sociedad en general y a las mujeres, en particular. De este modo, esta violencia simbólica se vuelve difícil de distinguir y señalar debido que la dominación masculina ha dejado marca en el inconsciente de cada uno/a que es parte de este sistema androcéntrico. $Y$ es en el momento en que las mujeres -en este caso, Yamila y Leila- salen de esos esquemas asignados, brotan posicionamientos que reniegan de ello y que tienen como arma a la violencia. Es por esto que la violencia de género debe comprenderse como un componente casi siempre presente en las problemáticas que perturban a las mujeres, debido que históricamente han sido despojadas de la oportunidad de decidir sobre sus cuerpos.

Lo que pretende exponer este ensayo es que el feminicidio continúa siendo un tópico pendiente para los medio de comunicación. En este caso, Diario de Cuyo no enfatizó ni analizó las muertes de Yamila y Leila como crímenes de odio asociados al género -muertas por ser mujeres-; es decir, como feminicidios.

Otro punto a resaltar es que cuando el medio reemplaza feminicidio por la palabra asesinato, manifiesta que esta sociedad está regida por la heteronormatividad. En este sentido, Diario de Cuyo en sus discursos ratifica esta postura desde el poder, frente a las víctimas de feminicidios y del modo en que decidió informar sus muertes. Estos discursos han sido construidos desde lo masculino, patriarcalmente, como un reflejo de cómo esta sociedad piensa y erige las relaciones o valora la vida de las mujeres en estos casos presentados. 
Notas

(1) "Proceso a través del cual la conducta no escrita, el habla, las creencias, la tradición oral y el ritual son caracterizados como un corpus, como un conjunto potencialmente significativo separado de toda situación discursiva o performativa inmediata. En el momento de la textualización este corpus significativo asume una relación más o menos estable con un contexto; ya estamos familiarizados con los resultados de este proceso, a través de o que se conoce como la descripción densa etnográfica" (Clifford, 2001: 58).

\section{Bibliografía}

Bourdieu, P. (2000). La dominación masculina. Barcelona: Anagrama.

Butler, J. (2006). Deshacer el género. Barcelona: Paidós.

Butler, J. (2004). Lenguaje, poder e identidad. Barcelona: Síntesis.

Clifford, J. (2001). Dilemas de la cultura. Antropología, literatura y arte en la perspectiva posmoderna. Barcelona: Gedisa.

Foucault, M. (1996). El orden del discurso. Madrid: Fábula.

Foucault M. (2002). La arqueología del saber. México: Siglo XXI.

Lagarde, M. (2012). Violencia femicida y derechos humanos de las mujeres. Recuperado de http://www.ankulegi.org/wp-content/uploads/2012/03/0008Lagarde.pdf

Pateman, C. (1995). El contrato sexual. Barcelona: Anthropos.

Ricoeur, P. (1988). El discurso de la acción. Madrid: Cátedra,

Segato, R. (2013). Las nuevas formas de la guerra y el cuerpo de las mujeres (1a. edición). Puebla: Pez en el árbol. Recuperado de http://www.feministas.org/IMG/pdf/libro_ritalaurasegato.pdf

Tillly, C. (2007). Violencia Colectiva. Madrid: Trillas.

Van Dijk, T. (2003). Ideología y discurso, una introducción multidisciplinaria. Barcelona: Ariel. Vasilachis, I. (1997). Discurso político y prensa escrita. Barcelona: Gedisa.

Zizek, S. (2009). Sobre la violencia, seis reflexiones marginales. Barcelona: Paidós.

\section{Artículos consultados}

Encontraron a una joven muerta en un baldío. Diario de Cuyo. Recuperado de https://www.diariodecuyo.com.ar/policiales/Encontraron-a-una-joven-muerta-en-unbaldio-20180618-0023.html 
Macabro: el cuerpo de la joven hallado en el baldío no tiene brazos y le falta parte del rostro (18 de junio de 2018). Diario de Cuyo. Recuperado de https://www.diariodecuyo.com.ar/policiales/Macabro-el-cuerpo-hallado-en-el-baldio-notenia-brazos-ni-parte-del-rostro-20180618-0026.html

Reforzarán el rastrillaje para hallar las partes mutiladas de la mujer (18 de junio de 2018). Diario de Cuyo. Recuperado de https://www.diariodecuyo.com.ar/policiales/Reforzaranel-rastrillaje-para-hallar-las-partes-mutiladas-de-la-mujer-20180618-0128.html

Buscan en la escena del crimen las pistas que el cuerpo no entrega (18 de junio de 2018). Diario de Cuyo. Recuperado de https://www.diariodecuyo.com.ar/policiales/Buscan-enla-escena-del-crimen-las-pistas-que-el-cuerpo-no-entrega-20180618-0068.html

La mujer mutilada tenía los pantalones bajos y no descartan un previo ataque sexual (18 de junio de 2018). Diario de Cuyo. Recuperado de https://www.diariodecuyo.com.ar/policiales/Mujer-mutilada-pantalones-bajos-y-ropainterior-puesta-no-descartan-un-previo-ataque-sexual-20180618-0045.html

La matan, le sacan el rostro, le cortan los brazos y tiran el cuerpo en un basural (19 de junio de 2018). Diario de Cuyo. Recuperado de https://www.diariodecuyo.com.ar/policiales/Lamatan-le-sacan-el-rostro-le-cortan-los-brazos-y-tiran-el-cuerpo-en-un-basural20180618-0145.html

La joven hallada en Chimbas murió por 8 puñaladas en el cuello y el tórax (19 de junio de 2018). Diario de Cuyo. Recuperado de https://www.diariodecuyo.com.ar/policiales/Lajoven-hallada-en-Chimbas-murio-por-8-punaladas-en-el-cuello-y-el-torax-201806190009.html

Creen que la mujer mutilada fue madre recientemente (19 de junio de 2018). Diario de Cuyo. Recuperado de https://www.diariodecuyo.com.ar/policiales/Creen-que-la-mujermutilada-fue-madre-recientemente-20180619-0039.html

Identificaron a la mujer mutilada: Yamila Pérez, era de Concepción y fue madre en mayo (19 de junio de 2018). Diario de Cuyo. Recuperado de https://www.diariodecuyo.com.ar/policiales/Identificaron-a-la-mujer-asesinada-en-ElMogote-se-llamaba-Yamila-Perez-era-de-Concepcion-y-habia-sido-mama-en-mayo20180619-0059.html

Dicen que la mujer asesinada y mutilada sería oriunda de Concepción (19 de junio de 2018). Diario de Cuyo. Recuperado de https://www.diariodecuyo.com.ar/policiales/Dicen-quela-mujer-asesinada-y-mutilada-seria-oriunda-de-Concepcion-20180619-0047.html 
El perfil social de Yamila: tenía al menos 4 cuentas en Facebook (19 de junio de 2018). Diario de Cuyo. Recuperado de https://www.diariodecuyo.com.ar/policiales/Dicen-que-lamujer-asesinada-y-mutilada-seria-oriunda-de-Concepcion-20180619-0047.html

Encontraron a una mujer muerta en un descampado de Ullum e investigan las causas (27 de junio de 2018). Diario de Cuyo. Recuperado de https://www.diariodecuyo.com.ar/policiales/Encontraron-a-una-mujer-muerta-en-undescampado-de-Ullum-e-investigan-las-causas--20180627-0052.html

Creen que Leila sufrió un ataque sexual y terminaron con ella matándola a golpes (28 de junio de 2018). Diario de Cuyo. Recuperado de https://www.diariodecuyo.com.ar/policiales/Creen-que-Leila-sufrio-un-ataque-sexual-yterminaron-con-ella-matandola-a-golpes-20180627-0109.html

El crimen de Leila: un fuerte golpe en la cabeza, marcas en el cuello y signos de violación (27 de junio de 2018). Diario de Cuyo. Recuperado de https://www.diariodecuyo.com.ar/policiales/El-crimen-de-Leila-un-fuerte-golpe-en-lacabeza-marcas-en-el-cuello-y-signos-de-violacion-20180627-0087.html

Muerte en Ullum: ¿Quién era Leila? (27 de junio de 2018). Diario de Cuyo. Recuperado de https://www.diariodecuyo.com.ar/policiales/Muerte-en-Ullum-Quien-era-Leila-201806270066.html

El mensaje de una vecina de Ullum por la muerte de Leila: "Tenemos miedo" (28 de junio de 2018). Diario de Cuyo. Recuperado de https://www.diariodecuyo.com.ar/policiales/Duro-mensaje-de-una-vecina-de-Ullum-porla-muerte-de-Leila-Tenemos-miedo-20180628-0012.html

Crimen de Leila: su expareja y padre de su hija es el único detenido (28 de junio de 2018). Diario de Cuyo. Recuperado de https://www.diariodecuyo.com.ar/policiales/Crimen-deLeila-su-expareja-y-padre-de-su-hija-es-el-unico-detenido-20180628-0019.html

El padre de la hija de Leila, contra las cuerdas por pruebas clave (28 de junio de 2018). Diario de Cuyo. Recuperado de https://www.diariodecuyo.com.ar/policiales/El-padre-de-lahija-de-Leila-contra-las-cuerdas-por-pruebas-clave-20180628-0057.html

Leila fue asesinada de tres puñaladas: una de ellas le perforó un pulmón (28 de junio de 2018). Diario de Cuyo. Recuperado de https://www.diariodecuyo.com.ar/policiales/Leila-fueasesinada-de-tres-punaladas-una-de-ellas-le-perforo-un-pulmon--20180628-0102.html

A Leila le dieron 2 golpes en la cabeza y 4 cuchillazos, uno de ellos la desangró (29 de junio de 2018). Diario de Cuyo. Recuperado de https://www.diariodecuyo.com.ar/policiales/A- 
Leila-le-dieron-2-golpes-en-la-cabeza-y-4-cuchillazos-uno-de-ellos-la-desangro20180628-0144.html

Tranquilo, buen padre e incondicional con Leila, así definen al sospechoso del crimen $(29$ de junio de 2018). Diario de Cuyo. Recuperado de https://www.diariodecuyo.com.ar/policiales/Tranquilo-buen-padre-e-incondicional-conLeila-asi-definen-al-unico-detenido-por-el-crimen-20180629-0045.html 